\title{
Fire resistance of prefabricated monolithic slab
}

\author{
Marina Gravit ${ }^{1}$, Ekaterina Nedviga ${ }^{1,{ }^{*}}$, Natalia Vinogradova ${ }^{1}$ and Zhanna Teplova ${ }^{1}$ \\ ${ }^{1}$ Peter the Great Saint-Petersburg Polytechnic University, 195251 Saint-Petersburg, Russia
}

\begin{abstract}
A prefabricated monolithic slab (PMS) has a number of valuable advantages, they allow to significantly decrease the weight of construction keeping the necessary structural-load capacity, to speed up and cheapen work conduction, to increase the heat isolating properties of an enclosure structure [1]. In order to create a design method of prefabricated monolithic slab fire-resistance, it's necessary to perform a series of PMS testing, one of which is being described in this article. Subjected to the test is a fragment of prefabricated monolithic slab with polystyrene concrete inserts along the beams with bent metal profile 250 $\mathrm{mm}$ thick, with a $2.7 \mathrm{~m}$ span loaded with evenly spread load equal to 600 $\mathrm{kg} / \mathrm{m} 2$. After 3 hour testing for fire-resistance [2] no signs of construction ultimate behavior were detected.
\end{abstract}

\section{Introduction}

The prefabricated monolithic slab (PMS) is a new cost-efficient construction type. Prefabricated monolithic slab allows to significantly decrease a construction weight keeping the necessary structural-load capacity of the construction, to speed up and cheapen work conductions, to increase the heat isolating properties of an enclosure structure [3].

It should be noted that the significant advantage of PMS structures lies in their environmental friendliness. For example, according to the Ministry of Environment of Finland, cellular concrete belongs to the best class of environmental safety. These data is in complete accord with the Russian ecologists' opinion. The Ministry of Health of the USSR in its time has developed the ecological index of building materials. The index asses the human exposure to the particular material and its environmental impact at all stages of the life cycle - from extraction of raw materials and its processing to recycling. The tree with the index 1.0 is considered to be the most environmental friendly. The index of autoclaved aerated concrete (aerated concrete), used as a filler in the PMS construction, is 2.0. For comparison, a ceramic brick has 10.0, claydite -20.0 . This means that by expanding the use of PMS aggregated with aerated concrete, the share of environmentally friendly building designs can be significantly increased in total number [4-6].

The share of prefabricated monolithic slabs in the EU countries according to the different estimates fluctuates from $20 \%$ to $35 \%$. In Russia PMS came into use only in 2008,

\footnotetext{
*Corresponding author: marina.gravit@mail.ru
} 
due to absence of legal framework, regulating application of PMS in industrial and civil construction [7].

The load bearing constructions applied demands are provision of bearing capacity under normal utilization conditions, and demands to provide fire protection of construction during the necessary period of time.

In European countries civil and structural reinforced concrete building engineering, as well as construction fireproof analysis are held in accordance with EN 1992:EUROCODE 2 [8]. In the Russian Federation reinforced concrete building designs under fire conditions are held in accordance with STO 36554501-006-2006 [9] which does not subject the prefabricated monolithic slab.

The authors analyzed the fireproof testing of Russian-manufactured prefabricated monolithic slabs by Russian PMS-systems manufacturer "Marko" [10] performed at testing facility OOO "PozhStandard".

\section{Slabs «Marko» which made from beams with metal molded section}

Prefabricated monolithic slabs have low own weight, combining the advantages of monolithic and prefabricated constructions. [11-15]

Prefabricated monolithic slab consists of beams placed close to each other, molding blocks filling the space between the beams, and monolithic concrete, poured above the fabricated construction at the construction site (Fig.1).

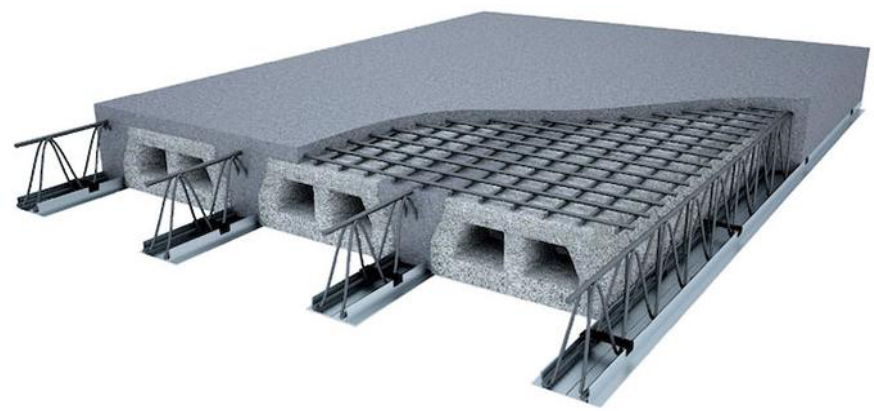

Fig.1 Slabs «Marko» which made from beams with metal molded section

Hollow or solid blocks of various materials like expanded clay lightweight concrete, aerated concrete, polystyrene concrete, high weight concrete, wood are used as light filler blocks in the prefabricated monolithic slabs. Aeroconcrete and claydite concrete have a high fireproof ability, according to classification they refer to non-combustible materials. For example, the wall made of $200 \mathrm{~mm}$. thick aeroconcrete blocks has the fire endurance period of $240 \mathrm{~min}$., the wall made of $150 \mathrm{~mm}$ thick claydite concrete blocks has the fire endurance period of $90 \mathrm{~min}$.

The expanded polysterene concrete refers to flammability class G1 (low flammable) according to GOST (all-union standard) 30244-94 and flammability group B1 (hardly flammable) according to GOST 30402-96 [16-17].

It seems reasonable to suppose that PMS aggregated with a non flammable material has greater fire endurance period rather than PMS aggregated with flammable and low flammable materials [18-19]. The slab's fragment was tested in order to confirm and study the work details and determination of the constructions' fire endurance period. 
A sample for further testing was the prefabricated monolithic slab, performed by the MARKO-UNIVERSAL type beams with the triangular reinforcement frame and bent metal profile (Fig.2). The polystyrene concrete blocks were used as filler blocks.

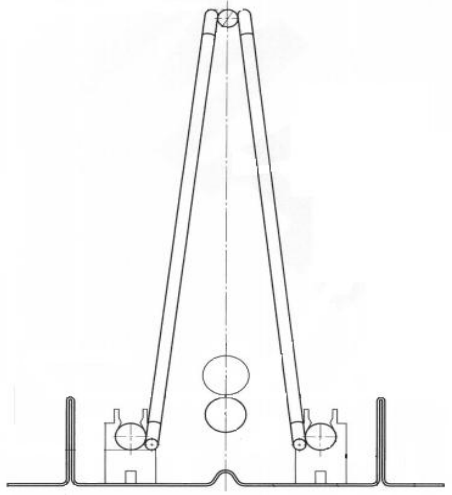

Fig.2 Cross section of beam «Marko- Universal»

\section{Protection of building constructions from fire impact}

Building or construction should be engineered and built in such a way that in case of a fire such requirements as maintenance of building or construction sustainability [20] and preservation of building bearing constructions strength during the time necessary to safely evacuate the people and perform other actions, aimed at decreasing the amount of loss caused by the fire and limiting the formation and spread of fire hazards within the fire. That is why during engineering of bearing constructions one must pay special attention to their fire resistance. The indicator of construction fire resistance is the fire endurance period.

The fire endurance period of a reinforced concrete construction is reached when the working reinforcement is heated up to a critical temperature, as well as when concrete is heated in its reference section above its critical temperature.

The fire endurance period of building constructions is a time limit set in minutes to occurrence of one or a number of ultimate conditions signs, specified for a given construction.

- Loss of structural-load capacity R;

- Loss of integrity E;

- Loss of thermal insulating capacity I.

It is typical for rod-type bearing reinforced concrete constructions (columns, beams, girders etc.) that fire endurance period is occurred only due to a sign of the a structural-load capacity loss. The flat bearing reinforced concrete constructions (ceiling panels, inner and outer walls) reach the fire endurance period mostly because of a sign of structural-load capacity loss, and only in some cases - due to thermal insulating capacity loss [21].

The fire endurance period of laminated enclosure structures by the thermal insulating capacity is equal to and over the sum of the fire endurance periods of each layer.

The fire endurance period of the load-bearing constructions is reduced along with the increase in load. As a rule, the mostly stressed cross-section of the construction, determines the value of its limit [22-24].

The ultimate condition of a structure under fire is characterized by critical heating temperatures of reinforcement and concrete and breaking stresses resulting from decrease of concrete and reinforcement resistance caused by heating. [25-27] 
The desired fire resistance of reinforced concrete constructions can be achieved in different ways:

- Designing an optimal cross section of a construction, for which the ultimate condition won't happen within the necessary fire endurance period;

- Use of fire protection means for building constructions, including the ones with heat isolating properties. [28-30]

In most cases, the second way is much expensive and requires additional time. Also some fire proof coverings and materials have their specified expiration date. Upon reaching this date, the re-use or free access to the construction for controlling the fire proof condition are required [31]. That's why, when engineering the reinforced concrete building constructions, parameters of constructions should be designed in order to ensure the sustainability of the load bearing elements to fire impact without constructional fire protection.

\section{Fire Test}

The concept of fire endurance test of building constructions is described in the international standard ISO 834-75 "Fire resistance test Elements of Building constructions (in an up-to date version of ISO 834-1:1999). As for the Russian construction standards on fire endurance, they base on the following international standards: ISO 834-75, ST SEV 100088 and some part of provisions of national standards BS 476-10; CSN 730-85, DIN 4102-2 and others [32-33].

In the Russian Federation the fire impact testing is performed in accordance to GOST 30247.0-94 "Building constructions. Concepts of fire endurance testing. General requirements", by the requirements it is identical to this standard [2]. During the testing the ambient temperature should be from +1 to $+40^{\circ} \mathrm{C}$ and with air flow speed not exceeding 0.5 $\mathrm{m} / \mathrm{s}$, if the construction conditions of usage do not require different testing parameters.

During the testing process the time and kind of ultimate conditions occurrence, temperature in the heating stove, temperature on the heated surface of the construction, excessive pressure in the heating stove during the construction testing, deformation of the load bearing constructions, time of flame appearance on the unfired heated surface of the piece, time of appearance and nature of cracks, holes, and stratification, and other things (such as breaking mounting conditions, appearance of smoke) are to be registered.

The temperature in the heating stove and temperature on the surface of pieces are varied through special thermoelectric temperature transducers - thermocouples.

The samples of the bearing constructions are to be tested under load. The testing load is set, based upon conditions of creating stresses in the cross sections of construction samples according to their engineered values or technical documentation. The load is set no later than 30 minutes before the start of the testing and is held constant with an accuracy of $\pm 5 \%$ during the whole testing period.

The samples of $250 \mathrm{~mm}$ [10] thick prefabricated monolithic slabs made in a beam form with bent metal profile were used as the test units. Dimensions of the construction are $3600 * 2000 \mathrm{~mm}$.

The construction samples of the prefabricated monolithic slabs in the given experiment were subjected to the test under equally-spread load of $600 \mathrm{~kg} / \mathrm{m} 2$. The design model of a structure is represented at fig.

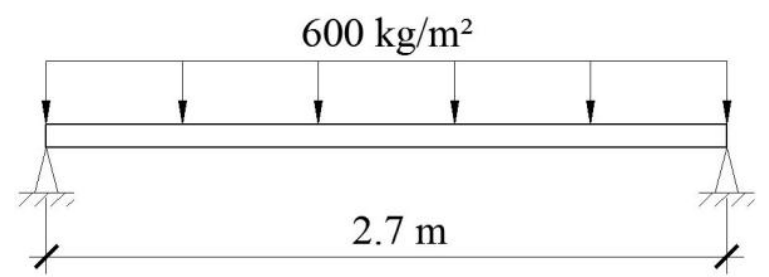

Fig.3 Analytical model of the structural sample 
The design load of $600 \mathrm{~kg} / \mathrm{m} 2$ corresponds to the average slab load of a residential or commercial unit, including the own weight of construction, floor, dividing walls, and temporary loads.

\section{Results of fire test}

During testing the following results were obtained: at 45 minutes of the testing the temperature in the heating stove had risen up to $880^{\circ} \mathrm{C}$, at 90 minute $\quad-$ up to $990^{\circ} \mathrm{C}$, at 180 minute - up to $1100{ }^{\circ} \mathrm{C}$.

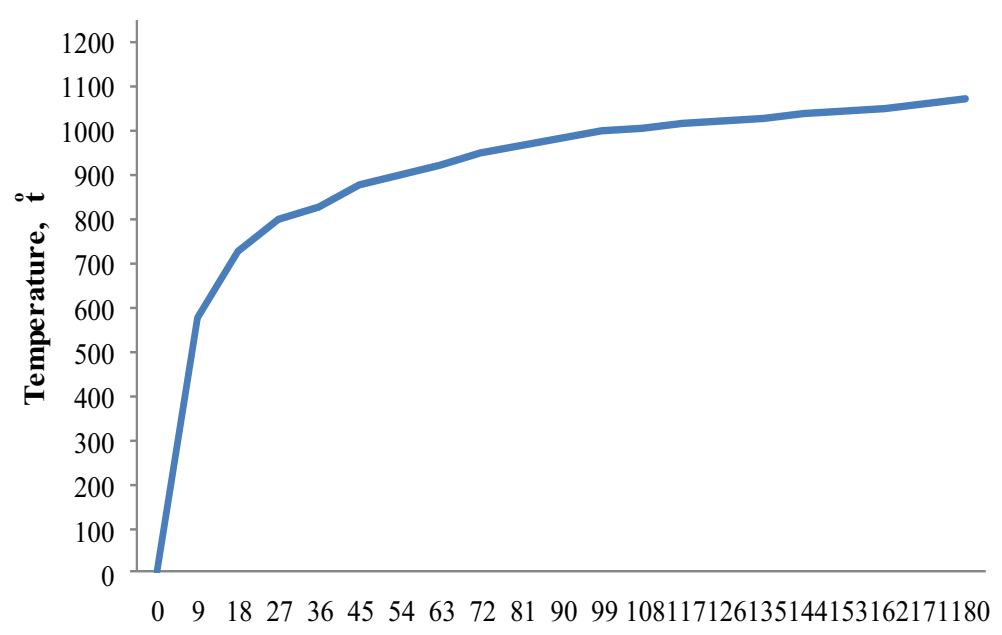

Time, minute

Average temperature in heating stove

Fig.4. Temperature development in heating stove

At that, the unfired concrete surface (in our case, the upper edge of the slab) at 45 minute of the testing the temperature was $36^{\circ} \mathrm{C}$, in 90 minute $-75^{\circ} \mathrm{C}$, and at 180 minute $-160^{\circ} \mathrm{C}$. 


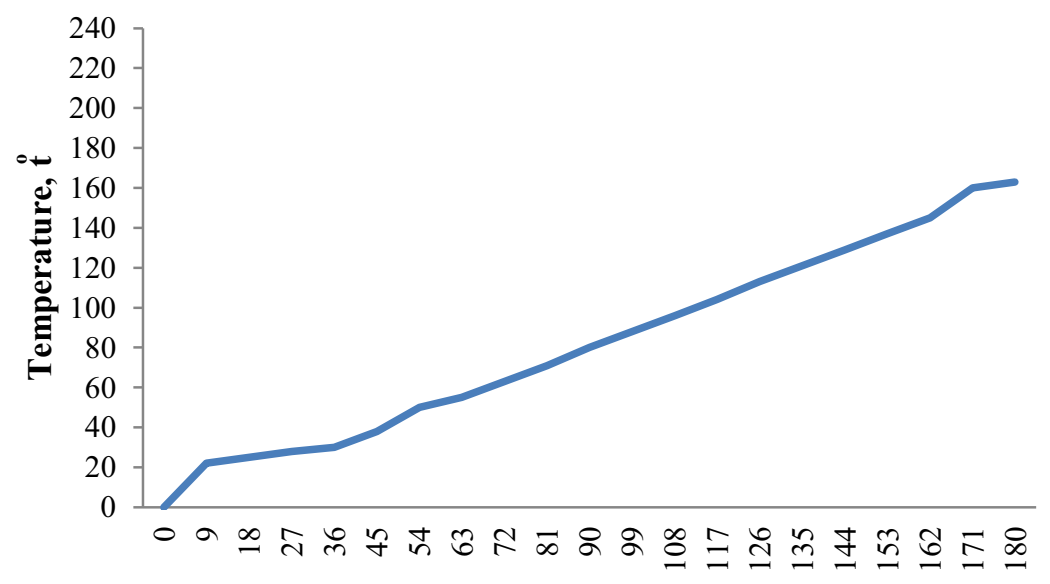

Time, minute

Average temperatute on unfired piece surface

Fig.5. Average temperature on unfired piece surface

According to [6], the critical temperature for heavy weight concrete with the silicate filler block is $500^{\circ} \mathrm{C}$, and critical temperature of reinforcement heating, which might have the plastic joint forming causing the fire endurance period occurrence, is approximately equal for reinforcement of classes: A $240 \ldots 500-510-550^{\circ} \mathrm{C}$; B $500-430^{\circ} \mathrm{C}$.

During the testing in an external condition of samples the following visual alterations were registered:

20 min - collapse of the basis and bordering walls of polystyrene concrete blocks in the area of the lower left corner of the panel;

$40 \mathrm{~min}$ - collapse of the basis and bordering walls of polystyrene concrete blocks in the area of the upper left corner of the panel;

$60 \mathrm{~min}$ - collapse of the basis and bordering walls of polystyrene concrete blocks in the area of the lower part of the panel;

$140 \mathrm{~min}$ - collapse of the basis and bordering walls of polystyrene concrete blocks in the area of the lower right corner of the panel;

$180 \mathrm{~min}$ - testing is finished in accordance with the customer.

During the testing, the loss of structural-load capacity (R) due to the collapse of the structure or ultimate deformation occurrence was not registered.

The loss of the thermal insulating capacity resulting from increase of the temperature on the unfired surface of constructions up to ultimate values for this construction (I) according to [2] of more than 140, in average, and on any point of surface of more than 180 compared to the construction temperature before testing, or more than 220 in no respect to surface temperature prior to testing (I), was not registered.

The loss of construction integrity as a result of occurrence of pervasive cracks or holes, through which products of combustion or flames (E) penetrate the unfired surface, is not registered.

The represented samples of prefabricated monolithic slabs have passed the testing in accordance with Russian and international standards. The actual time from beginning of a unilateral heat impact to occurrence of one of the regulated ultimate conditions of the sample piece of PMS "Marko" [10], fabricated on beams with bent metal profile, was 180 minutes, which matches the fire endurance period REI 180. 


\section{Summary}

Experimental studies have shown positive results of prefabricated monolith slab construction performance: the loss of the structural-load capacity resulting from the construction collapse, loss of the thermal insulating capacity, loss of integrity caused by penetrating cracks or holes in the construction were not registered after 180 minutes of testing.

Although for creation of the PMS fire protection design method it's not enough to have just one test conducted. That's why in the future it is planned to perform a series of fire resistance tests. It is planned to test the samples with an increased span, and also perform testing for slabs fire resistance with various light concrete inserts, such as aeroconrete, claydite concrete and polysterene concrete.

\section{References}

1. R.A. Sagadeyev, Construction of monolithic and cast-in-place building. Education guidance (2005)

2. ISO 834-75, Fire resistance tests Elements of building constructions

3. E.S. Nedviga, N.A. Vinogradova, Construction of Unique Buildings and Structures, 43, 87-102 (2016)

4. URL: http://www.ymparisto.fi/fi-FI/ Rakennuksen_energia_ja_ekotehokkuus (date of the address: 17.05.2016)

5. URL: http://www.ronl.ru/stati/stroitelstvo/204565/ (date of the address: 21.07.2016)

6. A.N. Ryazantsev, A.L.Lysenko, N.G. Rybal'skiy, V.V. Aleksashina, A.N. Tetior, E.D. Samotesov, V.V. Gorbatovskiy, I.V. Ignatovich, NIA-Priroda, Ecological safety in a construction complex (1999)

7. Z.S. Teplova, N.A. Vinogradova, Construction of Unique Buildings and Structures, 8 , 48-59 (2015)

8. EN 1992 EUROCODE 2 Design of concrete structures

9. STO 36554501-006-2006. Benefit by calculation of fire resistance and fire safety of steel concrete designs from heavy concrete

10. URL: http://www.kolumb.ru/smpp (date of the address: 21.07.2016)

11. A. Kaveh, A.F. Behnam, Scientia Iranica, 19, 410-416 (2012)

12. A.F. Al-Bayati, Lau Teck Leong, A. Clark Leslie, Structural Journal Concentric, 112, 533-542 (2015)

13. A.Abdolreza, Mark A. Bradford, X.Liu, Engineering Structures, Experimental study of composite beams having a precast geopolymer concrete slab and deconstructable bolted shear connectors, 114, 1-13 (2016)

14. J. Fernandez-Ceniceros, R. Fernandez-Martinez, E. Fraile-Garcia, F.J. Martinez-dePison, Automation in Construction, 35, 460-470 (2013)

15. Ibrahim Ahmed, Salim Hani, S. El-Din Hamdy, Engineering Structures, 33, 2644-2652 (2011)

16. URL: http://www.concrete-union.ru/articles/cellular_concrete.php?ELEMENT_ $\mathrm{ID}=5510$ (date of the address: 16.09.2016)

17. URL: http://stroypalata.ru/article2008.html (date of the address: 16.09.2016) 
18. D.E. Kolomiytsev, A.O. Rodicheva, V.A. Rybakov, Magazine of Civil Engineering, 8, 32-37 (2010)

19. I. Venanzi, M. Breccolotti, A. D’Alessandro, A.L. Materazzi, Fire Safety Journal, 69, 12-22 (2014)

20. A. Baran Eray, Engineering Structures, 98, 109-117 (2015)

21. V.V. Belov, K.V. Semenov, I.A. Renev, Magazine of Civil Engineering, 6, 58-61 (2010)

22. V. Korsun, N. Vatin, A. Franchi, A. Korsun, P. Crespi, S. Mashtaler, Procedia Engineering, 117, 970-979 (2015)

23. Z. Bonić, G. Topličić Ćurčić, M. Trivunić, N. Davidović, N. Vatin, Procedia Engineering, 117, 419-430 (2015)

24. Benefit by determination of limits of fire resistance of designs, limits of spread of fire on designs and groups of inflammability of materials (1985)

25. M. Heinisuo, M. Laasonen, J. Outinen, J. Hietaniemi, Application of Structural Fire Design, 405 - 410 (2011)

26. A.F. Milovanov, Firmness of reinforced concrete designs from fire (1998)

27. V.I. Korsun, A.V. Korsun, Improving Performance of Concrete Structures, 849-852 (2014)

28. A. Krivtcov, M. Gravit, S. Zimin, O. Nedryshkin, V. Pershakov, MATEC, Calculation of Limits of Fire Resistance for Structures with Fire Retardant Coating, 53 (2016)

29. M. Gravit, V. Gumenyuk, O. Nedryshkin, Procedia Engineering, 117, 114-118 (2015)

30. M. Gravit, V. Gumenyuk, M. Sychov, O. Nedryshkin, Procedia Engineering, 117, 119-125 (2015)

31. E.S. Nedviga, K.I. Solovyeva, S.S. Kiselev, Young Scientist, 24, 160-163 (2015)

32. M.V. Gravit, Standards and quality, 2, 36-37 (2014)

33. M.V. Gravit, Scientific forum with the international participation Week of science SPbPU, 48-51 (2015) 